\title{
Fire Risk-Based Evacuation Safety Derived from Statistical Analysis by Type of Building
}

\author{
HIROAKI NOTAKE ${ }^{1}$, YUKA IKEHATA ${ }^{2}$, JUN'ICHI YAMAGUCHI ${ }^{3}$, and TAKEYOSHI TANAKA ${ }^{4}$ \\ ${ }^{1}$ Institute of Technology \\ Shimizu Corporation \\ 3-4-17 Etchujima, Koto-ku, Tokyo, 135-8530, Japan \\ ${ }^{2}$ Technology Center \\ Taisei Corporation \\ 344-1, Nase-cho, Totsuka-ku, Yokohama, 245-0051, Japan \\ ${ }^{3}$ Technical Research Institute \\ Obayashi Corporation \\ 4-640, Shimokiyoto, Kiyose-shi, Tokyo, 204-8558, Japan \\ ${ }^{4}$ Disaster Prevention Research Institute \\ Kyoto University \\ Gokasho, Uji-shi, Kyoto, 611-0011, Japan
}

\begin{abstract}
The authors and their colleagues have been trying to construct a framework method of risk-based fire evacuation safety design for buildings. In the framework, it is necessary to determine a benchmark fire risk level to select design fires and scenarios appropriately. An attempt was made to develop this benchmark fire risk level by using 10 years of statistical data on residential fires. First, the acceptable evacuation risk for fire was established assuming that the level of evacuation risk for dwelling houses is the benchmark. Secondly, the fire statistics for buildings with different types of use was analyzed to establish a formula for the acceptable evacuation risk in the context of performance-based evacuation safety design that commonly holds for various types of use. Finally, there are discussions of other methods for determining the bench mark evacuation risk.
\end{abstract}

KEYWORDS: performance-based design, evacuation, acceptable risk, statistics.

\section{NOMENCLATURE LISTING}

\begin{tabular}{|c|c|c|c|}
\hline$A$ & floor area of design objective $\left(\mathrm{m}^{2}\right)$ & $R_{a}$ & $\begin{array}{l}\text { acceptable evacuation risk } \\
\text { (person/year) }\end{array}$ \\
\hline$C_{\text {cas }}$ & $\begin{array}{l}\text { casualty toll per hazardous fire } \\
\text { (person/fire) }\end{array}$ & $R^{D}$ & $\begin{array}{l}\text { design-based evacuation risk } \\
\text { (person/fire) }\end{array}$ \\
\hline$C_{0}^{D}$ & $\begin{array}{l}\text { design-based initial number of occupants } \\
\text { (person) }\end{array}$ & $R_{a l}^{D}$ & $\begin{array}{l}\text { design-based benchmark evacuation } \\
\text { risk on the basis of } C_{c a s} \text { (person/fire) }\end{array}$ \\
\hline$N_{h f}$ & annual number of hazardous fire (fire/year) & $R_{a 2}^{D}$ & $\begin{array}{l}\text { design-based benchmark evacuation } \\
\text { risk on the basis of } C^{D} \text { cas (person/fire) }\end{array}$ \\
\hline$N_{o c p}$ & number of occupants (person) & \multicolumn{2}{|c|}{ subscripts } \\
\hline$P$ & $\begin{array}{l}\text { probability of occurrence of hazardous fire } \\
\text { (fire/year) }\end{array}$ & & $\begin{array}{l}\text { acceptable } \\
\text { casualty }\end{array}$ \\
\hline$p_{\text {cas }}$ & $\begin{array}{l}\text { probability of casualty occurrence in } \\
\text { hazardous fire (/fire) }\end{array}$ & & $\begin{array}{l}\text { hazardous fire } \\
\text { occupant }\end{array}$ \\
\hline$p^{D}$ & $\begin{array}{l}\text { design-based density of occupant load } \\
\left.\text { (person } / \mathrm{m}^{2}\right)\end{array}$ & super & design-based \\
\hline$p_{h f}$ & $\begin{array}{l}\text { annual rate of occurrence in hazardous fire } \\
\text { per unit area (fire } / \mathrm{m}^{2} / \text { year) }\end{array}$ & $\begin{array}{l}\text { othei } \\
(H)\end{array}$ & $\begin{array}{l}\text { ndicators } \\
\text { dwelling }\end{array}$ \\
\hline$p_{\text {sty }}$ & rate of sojourn time at home & $(K)$ & objective building use \\
\hline$R$ & evacuation risk (person/year) & $(S)$ & specific building use \\
\hline
\end{tabular}




\section{INTRODUCTION}

In Japan, over 10 years have passed since a performance-based (P-B) design for evacuation safety was introduced by amendment of the Building Standard Law in June 2000 [1]. Many buildings have been designed by applying the performance-based verification method since then. Ten years have passed and we have found several problems in applying the evaluation method to P-B designs of actual buildings:

- In the existing prescriptive code, the fire safety provisions for large buildings and buildings available for general public are implicitly harder than those for other buildings. However, in the P-B verification method [1], we use uniform fire growing rates and criteria regardless of sizes of space and occupants. Therefore it is required to adjust the design fire conditions according to the size and the occupancy of fire origin.

- In the exiting P-B design method [1], though the differences of the evacuation safety level between different building types are empirically reflected, the differences between the rates of fire occurrence and casualty occurrence in fire still have not been considered.

- The deterministic approach has been adopted in the existing P-B design method [1]. So, several conditions in the fire scenario, such as smoke exhaust system and closing of fire doors and shutters will always work as expected.

- Since in the verification method [1], every room in a building has to be assumed and verified as a fire origin, fire safety engineers have to spend too much time working on verification for room evacuation safety. By contrast, they cannot give enough time and attention to the safety verification for corridors and stairs, which have a greater effect on floor and building evacuation safety.

For solving the problems mentioned above, a verification method based on a risk concept is considered to be beneficial. Though many methods based on a risk concept have been proposed [2-9], they have not yet been applied in real designs for evacuation safety, partly because the concept of accepting a certain number of casualties as the risk may not fit comfortably in the legal process, and partly because the acceptable level of risk has been difficult to determine.

Therefore, in order to develop the framework of a P-B fire safety design method based on risk concept, a verification method for evacuation safety that determines the design fires and scenarios based on the value of an evacuation risk was proposed [10,12-16].

In this paper, we seek to determine the values of the acceptable evacuation risk for fire safety design using the statistical data from fires in Japan.

\section{DEFINITION OF FIRE RISK}

In this paper, an evacuation risk in fire in the context of the risk-based evacuation safety design method (RB ESDM) is defined as an expected casualty toll. The risk is given as the product of the probability of the occurrence of a hazardous fire $P$ and the number of casualties caused by the fire $C_{c a s}$ as follows:

$R \equiv P C_{\text {cas }}$

Because the evacuation risk $R$ is to be used in R-B ESDM, we determine the underlying conditions for $P$ and $C_{c a s}$ as follows:

(1) It is assumed fires are always hazardous fires. A hazardous fire means a growing fire. Small fires, such as smoldering fires and/or self-extinguished fires, are disregarded as trivial.

(2) In Japan, the safety criteria in the exit evacuation safety verification are set at the level that people are not exposed or only slightly exposed to smoke, but not at the fatal level. Therefore evacuation failure is defined as the level of slight degree of injury or more.

If it is assumed that the probability of hazardous fire occurrence $P$ is proportional to floor area, $A$, so Eq. 1 can be rewritten as follows:

$R=p_{h f} \cdot A \cdot C_{c a s}$ 
The purpose of R-B ESDM is to control the evacuation risk for object building below an acceptable evacuation risk as follows:

$R \leq R_{a}$

In the context of R-B ESDM, the evacuation risk in an objective building use $K$, can be expressed as the derivation of Eq. 2 as follows:

$$
R(K)=p_{h f}(K) \cdot A(K) \cdot C_{c a s}(K)
$$

In R-B ESDM, we construct a scenario event tree and calculate the evacuation risk under the condition that a fire has occurred. Therefore, we substitute Eq. 4 into the left-hand side of Eq. 3, and transpose $p_{h f}$ and $A$ into the left-hand side as shown in Eq. 5. Hereafter in this paper, the term 'design-based' represents the parameters used in the context of ESDM, in other words, the parameters under the condition that a fire has occurred. In Eq. 5, the left-hand side is defined as the design-based evacuation risk $R^{D}$, and the right-hand side is defined as the design-based benchmark evacuation risk $R_{a}^{D}$ of objective building use $K$.

$R^{D}(K) \equiv C_{c a s}(K) \leq \frac{R_{a}}{p_{h f}(K) \cdot A(K)} \equiv R_{a}^{D}(K)$

In addition in this paper, the acceptable evacuation risk in Eq. 3 is defined as the evacuation risk of a specific building use $S$ as shown Eq. 6. In the context of R-B ESDM, it gives a threshold for the method.

$R_{a} \equiv p_{h f}(S) \cdot A(S) \cdot C_{c a s}(S)$

By substituting Eq. 6 into the right-hand side of Eq. 5, we obtain the following:

$R_{a 1}^{D}(K)=\left(\frac{p_{h f}(S)}{p_{h f}(K)}\right) \cdot\left(\frac{A(S)}{A(K)}\right) \cdot C_{c a s}(S)$

In R-B ESDM, we calculate $R^{D}$ on the basis of the design-based occupant load. Then it is necessary to adjust $C_{\text {cas }}(S)$ to the value on the design-based condition. Here, if it is assumed that we can obtain a probability of casualty occurrence in hazardous fire in the specific building use $S$ shown as $p_{\text {cas }}(S)$, the following equation is described:

$$
\begin{aligned}
& R_{a 2}^{D}(K)=\left(\frac{p_{h f}(S)}{p_{h f}(K)}\right) \cdot\left(\frac{A(S)}{A(K)}\right) \cdot C_{c a s}^{D}(S) \\
& =\left(\frac{p_{h f}(S)}{p_{h f}(K)}\right) \cdot\left(\frac{A(S)}{A(K)}\right) \cdot p_{c a s}(S) \cdot C_{0}^{D}(S)=\left(\frac{p_{h f}(S)}{p_{h f}(K)}\right) \cdot\left(\frac{A(S)}{A(K)}\right) \cdot p_{c a s}(S) \cdot A(S) \cdot p^{D}(S)
\end{aligned}
$$

Equation 7 and Eq. 8 give the design-based benchmark evacuation risk. The significant characteristic of these equations is that designers are able to calculate and obtain the upper limit of evacuation risk of their design object space from its floor area and type of use. In Eq. 7, the first term of right-hand side provides a ratio of hazardous fire occurrence and the second term gives a ratio of floor area between specific building use $S$ and design objective use $K$. If $K$ 's rate of fire occurrence gets bigger, or if $K$ 's floor area gets larger, the design-based benchmark evacuation risk $R^{D}{ }_{a}(K)$ gets smaller. So, the designers have to meet safety under a more conservative condition in the design fire scenario. 


\section{ANALYSIS METHOD OF RATE OF HAZARDOUS FIRE OCCURRENCE AND RATE OF CASUALTIES PER HAZARDOUS FIRE BY USING STATISTICAL DATA}

In the risk-based evacuation safety design method, it must be proved that the expectation of casualties in a building, $R^{D}(K)$, is lower than the design-based benchmark evacuation risk, $R^{D}{ }_{a}(K)$, which is derived from the statistical data on fires. The procedure to obtain the value of $R_{a}^{D}(K)$ is as follows,

(1) The $p_{h f}$, and $C_{c a s}$ for each building type are calculated by using the statistical data, replacing fire occurrence probability with annual fire occurrence rate.

(2) The values of the $p_{h f}$, and $C_{c a s}$ are substituted for Eq. 4, to obtain the evacuation risk in a space with the floor area $A$ for each building type. The median gross floor area of buildings in which there were hazardous fires are adopted as the floor area $A$.

\section{Statistical Data}

The rate of hazardous fire occurrence, $p_{h f}$, the rate of casualties per hazardous fire, $C_{c a s}$, the national total of the gross floor area, $A_{\text {gross }}$, and the median gross floor area are obtained from statistical data. The national building fires data from the fire report of Fire and Disaster Management Agency from 1995 to 2004 [11] was used to obtain the numbers of hazardous fires, casualties and the gross floor area of fire buildings of each occupancy type. As for the definition of fire, we identified 'hazardous fire' as that for which the floor damage area from fire is more than $1 \mathrm{~m}^{2}$, or the surface damage area from fire is more than $1 \mathrm{~m}^{2}$ in fire statistics except for arson-caused fires and external fires. The national total of the gross floor area was obtained from the Handbook of Energy \& Economic statistics published by the Energy Data and Modeling Center in Japan for the years from 1995 to 2004, except for apartments and dwellings, which are obtained from the fixed asset ledger. Because the floor area of non-wooden apartments and dwellings are classified into the category of non-wooden residence in the investigation outline of the fixed asset ledger, we derive the floor areas of non-wooden apartment from those of non-wooden dwelling by using the ratio of dwelling and apartment in non-wooden residences in the data of the Housing and Land Survey (every 5 years, the latest is the data of 2008).

\section{Calculation Method of Rate of Hazardous Fire Occurrence}

The rate of the hazardous fire occurrence is calculated by Eq. 9 assuming that the number of the hazardous fire occurrence is proportional to floor area. i.e.:

$$
p_{h f}(K)=\frac{N_{h f}(K)}{A_{\text {gross }}(K)}
$$

\section{RATE OF FIRE OCCUREENCE}

\section{Gross Floor Area in Each Building Type}

In the paper, nine building types, i.e., theater, restaurant, shop, hotel, apartment, hospital, school, office and dwelling are analyzed. The trend of the gross floor area in each building type is as shown in Fig. 1. The gross floor areas in 2004 rose to 1.06-1.37 times of those in 1995. Among those building types, rates of area increase are large in apartment (1.37), hospital (1.34) and shop (1.21). On the contrary, those are small in hotel (1.06), school (1.08) and restaurant (1.13).

\section{Number of Fire Occurrences in each Building Type}

The trend of the number of the hazardous fire occurrences for each building type is as shown in Fig. 2. In Fig. 2, the number of the hazardous fire occurrences in dwellings and restaurants increase, however, the other building types tend to be stable or decline slightly. The percentage of increase between 1995 and 2004 is $21 \%$ in restaurant and $15 \%$ in dwelling. 


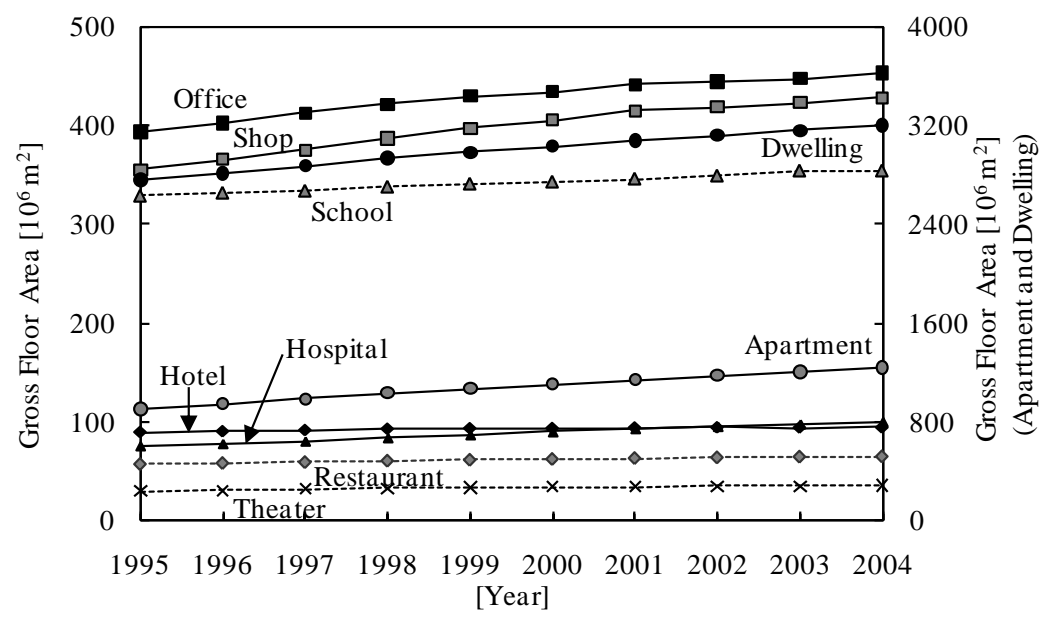

Fig. 1. Trend chart of gross floor area by type of building between 1995 and 2004.

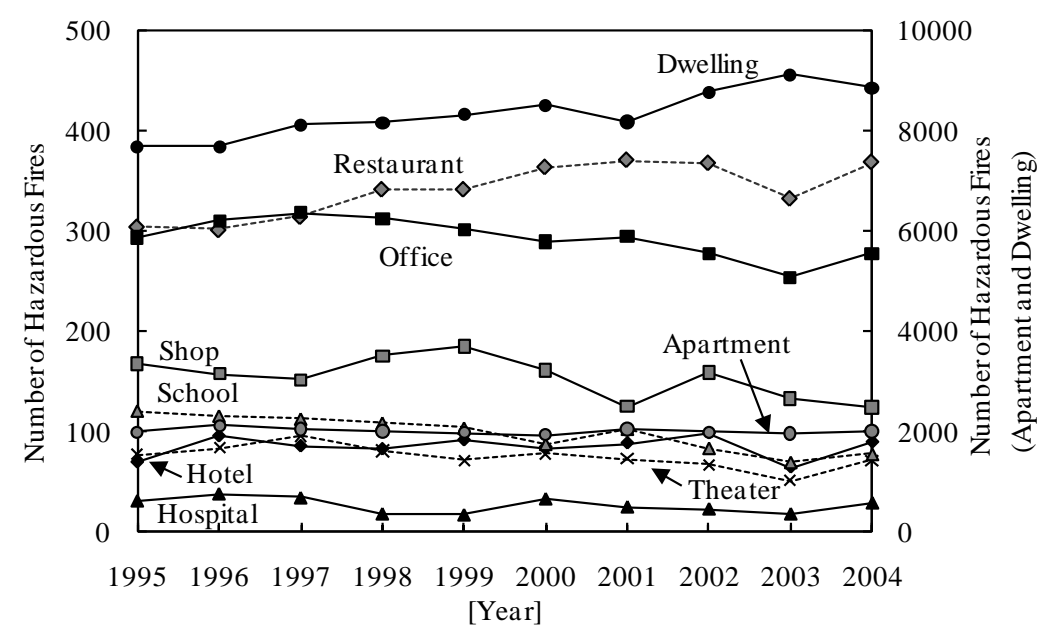

Fig. 2. Trend chart of number of hazardous fires by type of building between 1995 and 2004.

\section{Rate of Fire Occurrence by each Building Type}

The trend of the rate of the hazardous fire occurrence per area is as shown in Fig. 3. The numbers in the parentheses in the figure indicate the average and the standard deviation during 10 years.

The trend of hazardous fire occurrence rate per floor area has not changed much in most building types during the 10 years especially in apartment and theater buidings which have decreased. In Fig. 3, the rates of the hazardous fire occurrence rate per floor area are classified into three groups. The rate in restaurant, which is an occupancy that uses fire, is the highest at 5.6 hazardous fire $/ 10^{6} \mathrm{~m}^{2} /$ year, the middle group includes dwelling, theater and apartment, with $2.8,2.3$ and 1.9 hazardous fire $/ 10^{6} \mathrm{~m}^{2} / \mathrm{year}$, respectively. The lower group includes hotel, office, school, hospital and shop with 1.0 hazardous fire $/ 10^{6} \mathrm{~m}^{2} /$ year or less.

As for the standard deviation of yearly hazardous fire occurrence rate, dwelling (0.06), office (0.07) and shop (0.07) are low. It means those building types have had a more stable fire occurrence rate over the 10 years. 


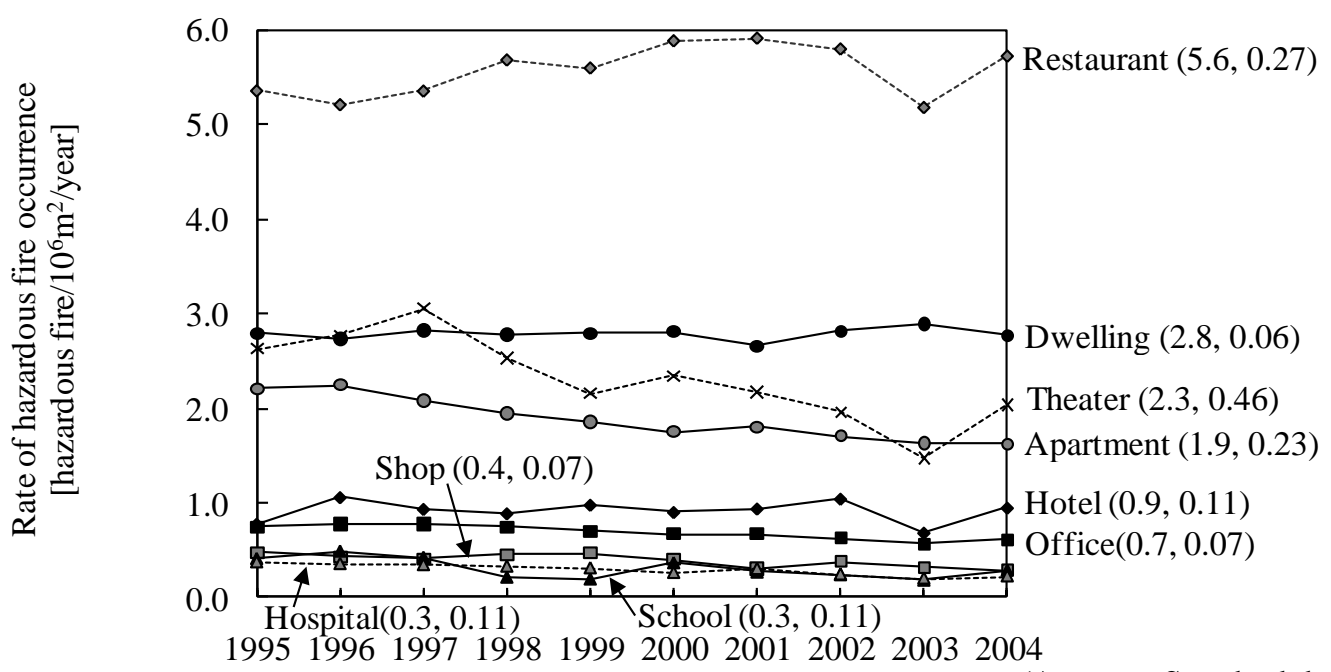

[Year]

(Average, Standard deviation)

Fig. 3. Rate of hazardous fire occurrence per floor area between 1994 and 2004.

\section{CASUALTY TOLL PER HAZARDOUS FIRE}

The casualty toll per hazardous fire, $C_{c a s}$, is calculated by using the statistical data of each building type. In this paper, the casualties include fatalities and slight injuries or more except for firefighters and suicide victims. As we consider that the $C_{c a s}$ is related to the occurrence time and occupants' behavior, the following three cases of the casualty tolls and the injury toll are calculated:

- The casualty toll per hazardous fire (average of total),

- The maximum hourly casualty toll per hazardous fire,

- The injury toll during the evacuation per hazardous fire.

\section{Trend of Hourly Casualty Toll per Hazardous Fire}

We calculate the hourly casualty toll per hazardous fire for each building type. The trend of casualties, hazardous fires, and its casualty toll per hazardous fire are shown in Fig. 4 and Fig. 5 by building type. As for the number of hazardous fires, the hourly lowest peak occurs between 4 a.m. and 6 a.m. in most building types. In restaurant, apartment and dwelling, a great number of hazardous fires occur in the evening and during the nighttime because occupants use fire for cooking. On the contrary, there are many fires in the daytime in schools, office and shop because many occupants are present in the building. Thus in most building types the number of hazardous fire is related to the hours that the occupants stay and undertake some sort of activities in the building, and the hours that the occupants use fires. 


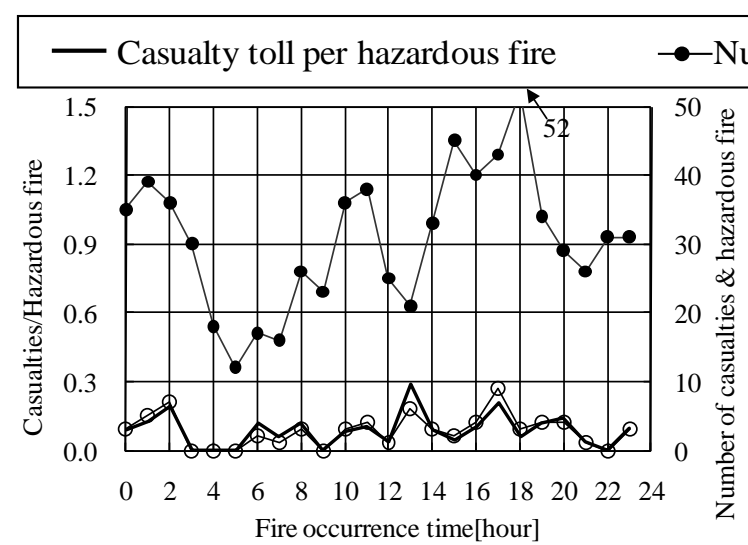

(a)

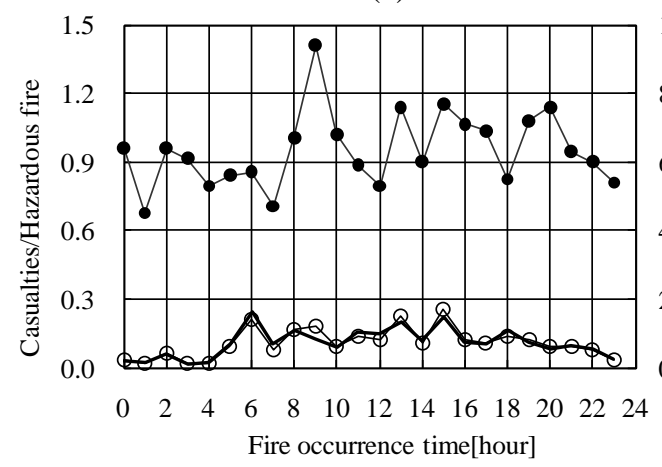

(c)

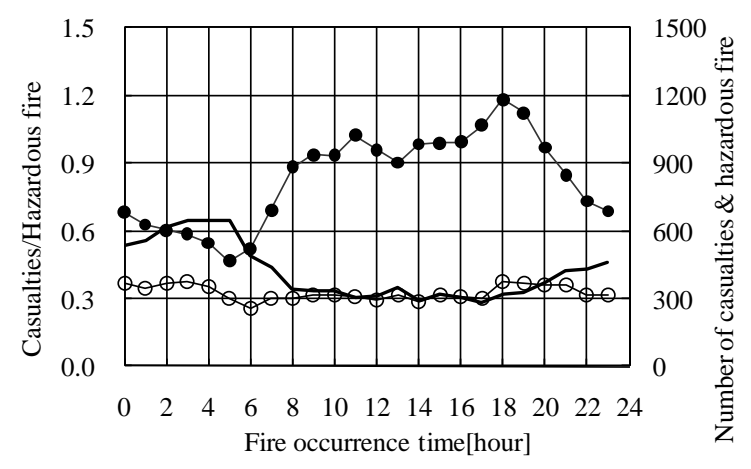

(e)

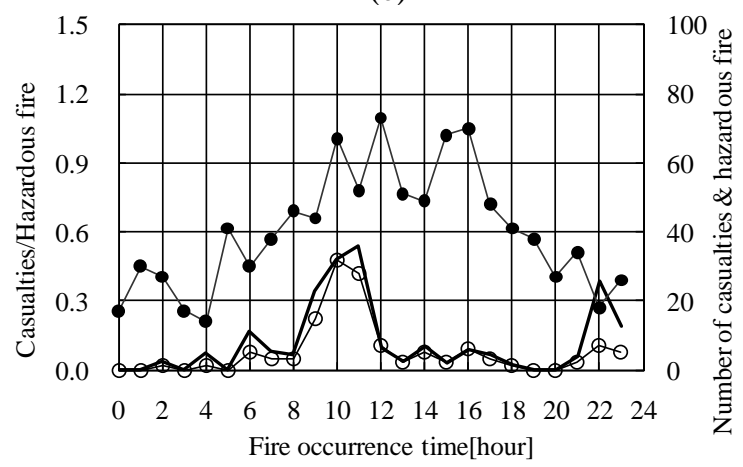

(g)

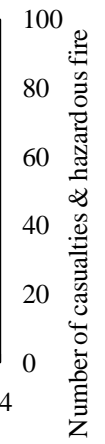

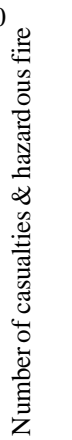

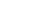

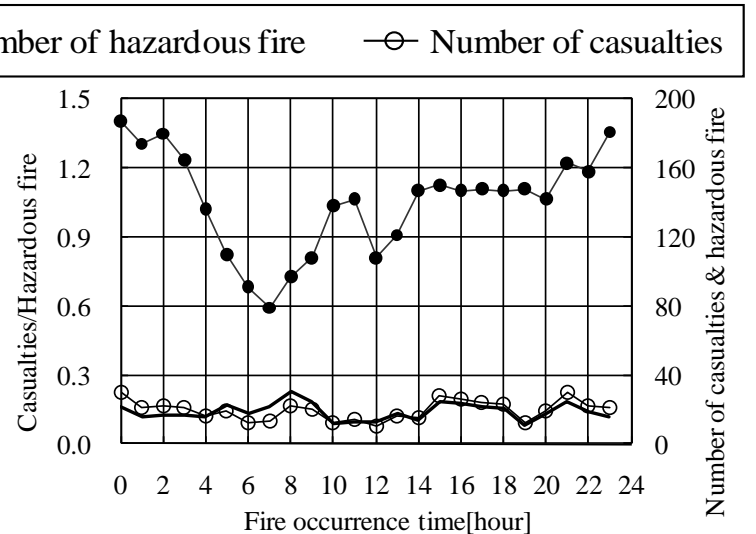

(b)

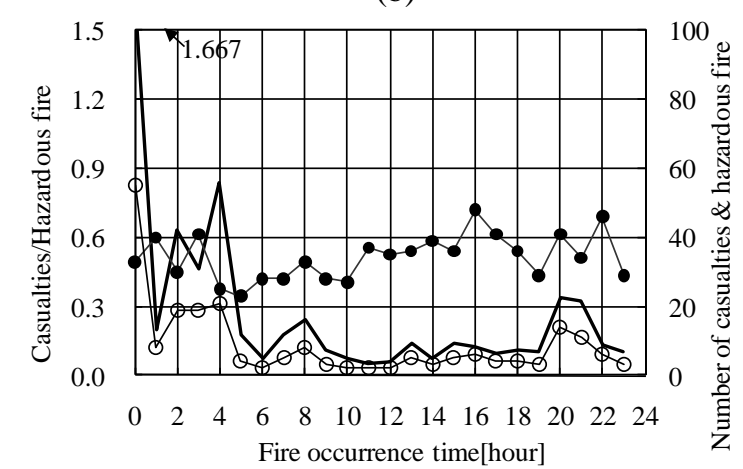

(d)

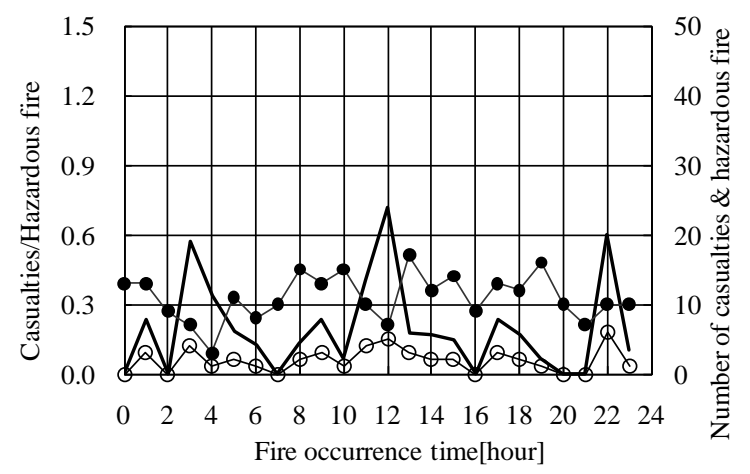

(f)

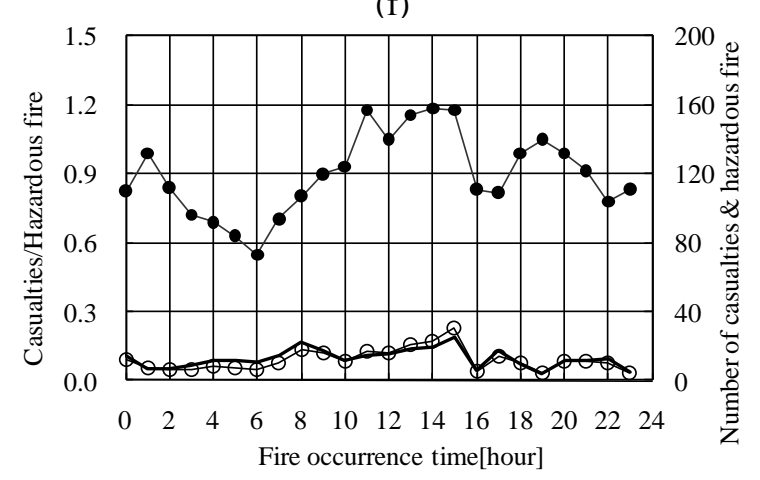

(h)

Fig. 4. Hourly trend for hazardous fire, fire casualties, and casualty toll per hazardous fire: (a) theater; (b) restaurant; (c) shop; (d) hotel; (e) apartment; (f) hospital; (g) school; (h) office. 


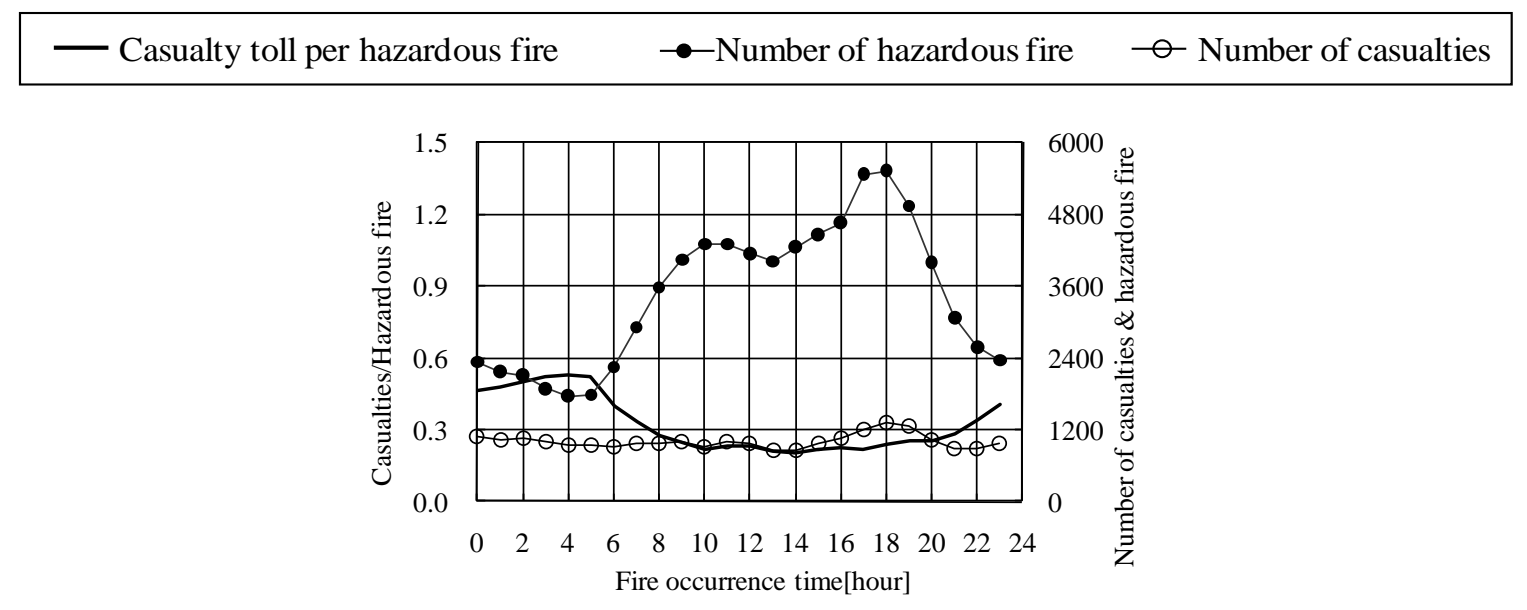

Fig. 5. Hourly trend for hazardous fire, fire casualties, and casualty toll per hazardous fire (in dwelling).

As for the hourly casualty toll per hazardous fire $C_{c a s}$, it is high in apartment, in dwelling and in hotel from midnight to early morning, when occupants are expected to stay in buildings and sleep in bed. The value of $C_{c a s}$ in shop, school and office also increases during daylight. Therefore, $C_{c a s}$ is related to time when people stay in buildings.

As for the features in hospital, first, the hourly fluctuation of occurrence of hazardous fire is smaller than any other building type. Secondly, although hospital has sleeping occupants, its hourly casualty tolls at nighttime are not as high as those in apartment, dwelling or hotel. Because of management system with nursing staff, prohibiting use of fire and so on, it might be controlled in occurrence of fire and casualty toll at nighttime.

The average and the maximum of hourly casualty toll per hazardous fire in building types are as shown in Table 1. In addition, the death toll and the fractions of fatalities in casualties are also shown in Table. 1. We can see the severity of fire as we check the fractions of fatalities. As for the fractions of fatalities, the value in residential buildings such as dwelling and apartment are higher than those in any other building types. The values in hospital and shop are secondary high among the building types. The lowest is in school that none of fatality is occurred in 10 years. As for the hourly average of $C_{c a s}$, there are also high in apartment, dwelling and hotel. As for the hourly maximum of $C_{c a s}$, the differences are more obvious between buildings with occupants in sleep such as hotel, apartment and dwelling, or those with disabilities i.e., hospital and school, and the others. Although the fraction of fatalities in apartment is lower than that in dwelling, the values of $\mathrm{C}_{\text {cas }}$ are higher than in apartment than in dwelling. Actually, it is 1.3 times as large as that in dwelling with regard to the maximum of $C_{c a s}$, and 1.1 times as large as with regard to the average of $C_{c a s}$. It is thought that apartment buildings consist of multiple residential units, and not only the occupants in fire origin but those in another residential unit are likely to be suffered by fire and smoke.

Table 1. Number and rate of casualties by hazardous fire.

\begin{tabular}{|c|c|c|c|c|c|c|c|c|c|c|c|}
\hline \multicolumn{3}{|c|}{\begin{tabular}{|l} 
Building type \\
Occupant suffering
\end{tabular}} & Theater & Restaurant & Shop & Hotel & Apartment & Hospital & School & Office & Dwelling \\
\hline \multicolumn{2}{|c|}{ Death toll } & [persons] & 2 & 21 & 14 & 13 & 1132 & 4 & 0 & 18 & 6826 \\
\hline \multicolumn{2}{|c|}{\begin{tabular}{|l|} 
Casualty toll \\
\end{tabular}} & [persons] & 66 & 470 & 170 & 220 & 7865 & 46 & 128 & 283 & 18999 \\
\hline \multicolumn{2}{|c|}{$\begin{array}{l}\text { Fraction of fatalities } \\
\text { in casualties }\end{array}$} & {$[-]$} & 0.03 & 0.04 & 0.08 & 0.06 & 0.14 & 0.09 & 0.00 & 0.06 & 0.26 \\
\hline \multirow{2}{*}{$C_{c a s}$} & Average & \multirow{3}{*}{$\begin{array}{c}\text { [Persons } \\
\text { /Hazardous } \\
\text { fire] }\end{array}$} & 0.09 & 0.14 & 0.11 & 0.26 & 0.39 & 0.17 & 0.13 & 0.10 & 0.29 \\
\hline & Maximum & & 0.29 & 0.23 & 0.25 & 1.67 & 0.65 & 0.71 & 0.54 & 0.14 & 0.53 \\
\hline \multicolumn{2}{|c|}{$\begin{array}{l}\text { Rate of casualties } \\
\text { during egress }\end{array}$} & & 0.02 & 0.02 & 0.01 & 0.10 & 0.08 & 0.02 & 0.03 & 0.01 & 0.05 \\
\hline
\end{tabular}




\section{Injury Toll per Hazardous Fire by their Behavior at Time of Injury}

In the fire statistical data, the behaviors of persons injured are classified as follows: (1) during fire fighting, (2) during evacuation, (3) while sleeping, (4) while working, (5) others(housekeeping, eating and drinking, taking a break and going to the rescue etc.)

Figure 6 shows the rate of the injured persons per hazardous fire grouped by the behaviors at the time of injury in each building type. The rate during firefighting is the highest except for hotel and hospital. The rate during an evacuation is higher in hotels and apartment buildings where people sleep in bed than other types of buildings. The rate of 'while sleeping' is low except for apartment, hotel and dwelling.

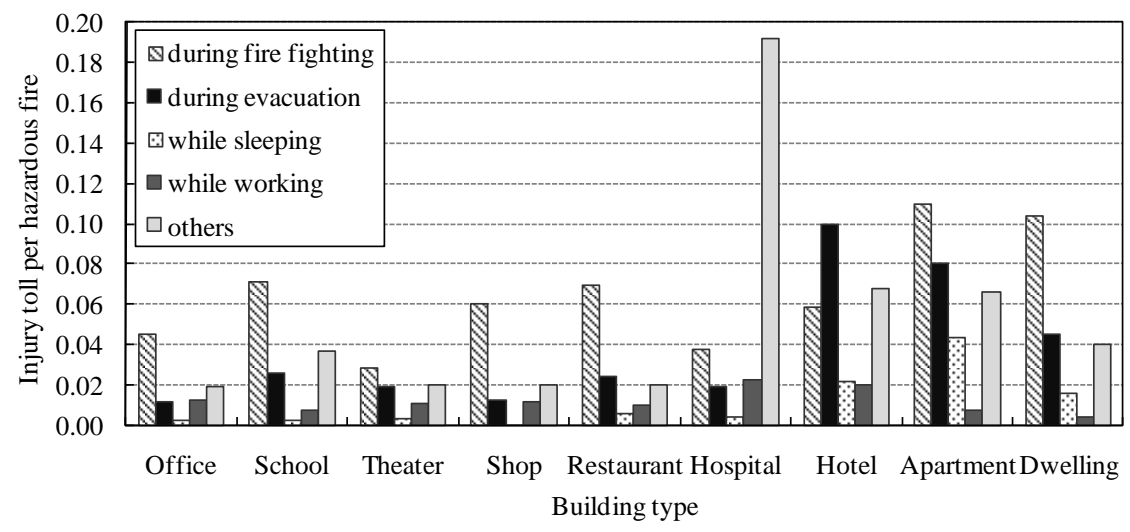

Fig. 6. Rate of injury per hazardous fire by action type at injury.

\section{ACCEPTABLE EVACUATION RISK}

Using the above statistical data, we try to estimate the evacuation risk, $R$, and the design-based benchmark evacuation risk, $R_{a}^{D}$, which is to be used in R-B ESDM of buildings.

\section{Evacuation Risk in each Building Type}

Table 2 shows the evacuation risk, $R(K)$, which are calculated by Eq. 4 . Here, we define as a representative evacuation risk $R_{\text {rep }}(K)$ adopting the median of the gross floor area in each building type from the fire statistical data, i.e. the gross floor area of the suffered buildings in fire in 10 years. The value of $p_{h f}, A$ and $C_{c a s}$, are shown in Table 2.

Table 2. Representative evacuation risk in building types $\left(R_{\text {rep }}(K)\right)$.

\begin{tabular}{|c|c|c|c|c|c|c|c|c|c|c|}
\hline \multicolumn{2}{|c|}{} & Theater & Restaurant & Shop & Hotel & Apartment & Hospital & School & Office & Dwelling \\
\hline$p_{h f}$ & Average & 2.3 & 5.6 & 0.4 & 0.9 & 1.9 & 0.3 & 0.3 & 0.7 & 2.8 \\
\hline \multirow{3}{*}{$C_{\text {cas }}$} & $\begin{array}{c}\text { Average } \\
\left(C_{\text {cas_ave }}\right)\end{array}$ & 0.09 & 0.14 & 0.11 & 0.26 & 0.39 & 0.17 & 0.13 & 0.10 & 0.29 \\
\cline { 2 - 12 } & $\begin{array}{c}\text { Maximum } \\
\left(C_{\text {cas_max }}\right)\end{array}$ & 0.29 & 0.23 & 0.25 & 1.67 & 0.65 & 0.71 & 0.54 & 0.14 & 0.53 \\
\hline$p_{h f \times} \times$ & With $C_{\text {cas_ave }}$ & 0.21 & 0.77 & 0.04 & 0.24 & 0.74 & 0.05 & 0.04 & 0.07 & 0.82 \\
\cline { 2 - 12 }$C_{\text {cas }}$ & With $C_{\text {cas_max }}$ & 0.66 & 1.27 & 0.10 & 1.50 & 1.23 & 0.21 & 0.16 & 0.10 & 1.48 \\
\hline$A$ & Median & 159 & 187 & 262 & 625 & 464 & 827 & 1731 & 155 & 118 \\
\hline \multirow{2}{*}{$R_{\text {rep }}$} & With $C_{\text {cas_ave }}$ & 0.3 & 1.4 & 0.1 & 1.5 & 3.4 & 0.4 & 0.7 & 0.1 & 1.0 \\
\cline { 2 - 12 } & With $C_{\text {cas_max }}$ & 1.0 & 2.4 & 0.3 & 9.4 & 5.7 & 1.8 & 2.8 & 0.1 & 1.8 \\
\hline
\end{tabular}

Unit: $p_{h f}\left(10^{-6}\right.$ hazardous fire / $\left.\mathrm{m}^{2}\right), C_{\text {cas }}$ (persons / hazardous fire $), A\left(\mathrm{~m}^{2}\right), R_{\text {rep }}\left(10^{-4}\right.$ persons / year) 
In Table 2 , if we use the hourly average value $\left(C_{\text {cas_ave }}\right)$ as $C_{\text {cas }}$, the $R_{\text {rep }}$ in apartment is the highest as $3.4 \times 10^{-4}$ persons/year. And $R_{\text {rep }}$ in hotel (1.5), restaurant (1.4), and dwelling (1.0) are in secondary high group. If we use the hourly maximum value $\left(C_{\text {cas_max }}\right)$ as $C_{c a s}$, the $R_{\text {rep }}$ in hotel (9.4) and apartment $(5.7)$ are high. In theater, restaurant, hospital, school and dwelling, the risks are nearly at the same level, i.e. between 1.0 and $2.8 \times 10^{-4}$ persons/year. The $R_{\text {rep }}$ in shop and office are low whichever is used as $C_{c a s}$, i.e. between 0.1 and $0.3 \times 10^{-4}$ persons/year. This is considered to be affected by the difference of the rate of hazardous fire occurrence and the hourly variation of $C_{c a s}$. Under the existing regulation, the evacuation risks are controlled to three levels, corresponding to type, i.e. buildings with sleeping facilities (apartment, dwelling, hotel), buildings where fires are frequently used (restaurant) and the others.

\section{Alternatives with Regard to Setting the Acceptable Evacuation Risk and their Features}

As we mentioned at Eq. 3, the purpose of R-B ESDM is to control the evacuation risk for object building below the acceptable evacuation risk. So it is important how to set the acceptable risk $R_{a}$ derived from Eq. 6 . If we set the acceptable risk level at a relaxed level, the attained safety level may go down. On the other hand, if we set the risk level at an exceedingly strict level, it may become impossible to obtain practicable solutions to satisfy the level. So we need to determine the acceptable level carefully.

In this section, we consider the following four alternatives in setting the $R_{a}$, and discuss the pros and cons in each alternative.

(1) Set different representative evacuation risk $R_{\text {rep }}$ (here, $R_{\text {rep }}$ is obtained substituting the median of gross floor area in fire statistics for $A$ ) as $R_{a}$ for each different type of use of building.

(2) Set the representative evacuation risk in dwelling commonly for all types of use $\left(R_{\text {rep_Dwelling }}=1.0 \times 10^{-4}\right)$ as $R_{a}$.

(3) Set the lowest representative evacuation risk commonly for all types of use; i.e. that in office and shop $\left(R_{\text {rep_office }}=R_{\text {rep_Shop }}=1.0 \times 10^{-5}\right)$ as $R_{a}$.

(4) Set the acceptable level broadly used in risk management $\left(1.0 \times 10^{-6}\right)$ as $R_{a}$.

For reference, we calculate the evacuation risk $R$ by using Eq. 4 adopting $C_{c a s}$ from Table 1, $p_{h f}$ from Fig. 3 as a fixed value for each building type. As for the value of $A$ in Eq. 4, we substituted the value between the $25^{\text {th }}$ percentile and $95^{\text {th }}$ percentile of gross floor areas of buildings of fire origin in the fire statistics. The range of the evacuation risk $R$ according to the gross floor area $A$ in each building type is shown in Fig. 7 . The $\mathrm{x}$-axis is the gross floor area $A$ and the $\mathrm{y}$-axis is the evacuation risk $R$ derived from Eq. 4. Incidentally, the both axes in Fig. 7 are logarithmic. As expected, the levels of the evacuation risk are different from one building type to another.

The features of four alternatives are as follows:

(1) It is easy to sense the level of safety of the specific building among the same type of buildings because $R_{a}$ consists of parameters derived from the same building type. On the other hand, the representative risk level itself is difficult to determine since the range of floor area of a building type is very wide. For example for shops in Fig. 7, the floor areas vary from $118 \mathrm{~m}^{2}$ at the $25^{\text {th }}$ percentile to $7832 \mathrm{~m}^{2}$ at the $95^{\text {th }}$ percentile. So we might have many options to determine the representative risk level but cannot determine the definite level. Moreover, $R_{a}$ is quite different among building types, i.e. $R_{a}$ in Fig. 7 , from $3.4 \times 10^{-4}$ in apartment to $1.0 \times 10^{-5}$ in office and shop.

(2) It is easy to determine the representative evacuation risk level in dwelling because dwellings have relatively narrow range in gross floor area than other building types. In addition, the number of occupants is similar at every dwelling. Moreover dwelling has scarcely fire safety measures, so the current risk level can be deemed as the level without effects of them. On the contrary, the risk level depends on occupants' condition such as age, physical, sleeping, drinking etc much more than that in other building types. Accordingly, the risk level in dwelling is higher than any other building types, so there is a criticism that the risk level in dwelling is looser as the design-based acceptable level. As we compare the evacuation risks at the gross floor area as $100 \mathrm{~m}^{2}$ in Fig. 7, it is sure that the evacuation risk in dwelling is larger than that of other building types. But as we see the whole range of $R$ in all building type, the evacuation risk varies from $7.5 \times 10^{-5}$ persons/year to $5.0 \times 10^{-2}$ persons/year. So the evacuation risk of dwelling, which value is $1.0 \times 10^{-4}$ persons/year, is located in the relatively lower part of the range. 
(3) This is obviously the acceptable risk at safer side level than alternative (2). But this is thought to be the results that many fire protection measures are installed in existing offices and shops, such as smoke detector, fire compartment, sprinkler etc. Therefore current risk level includes effects of these fire protection measures. It is difficult to know if these fire protections have reduced the risk to exactly acceptable level or overshot the level.

(4) This is ideal as the acceptable risk level. But it is too far beyond the current risk level. If we adopt this alternative, we might have to provide many additional fire protection measures in order to meet the level in almost all kinds of building compared with current practical measures for evacuation safety.

As we described above, each alternative has both advantages and defects. So at the current moment, it is difficult to find any flawless alternative. We need to discuss more comprehensively about how to set the acceptable risk level for evacuation safety design method. For this purpose, more extensive case studies will be useful to seek for a reasonable level of acceptable risk. However, through by some simplified case study $[10,12]$, the authors have a prospect that the risk level of alternative (2) may be reasonable from the view point of the practical safety level for evacuation design of office building.

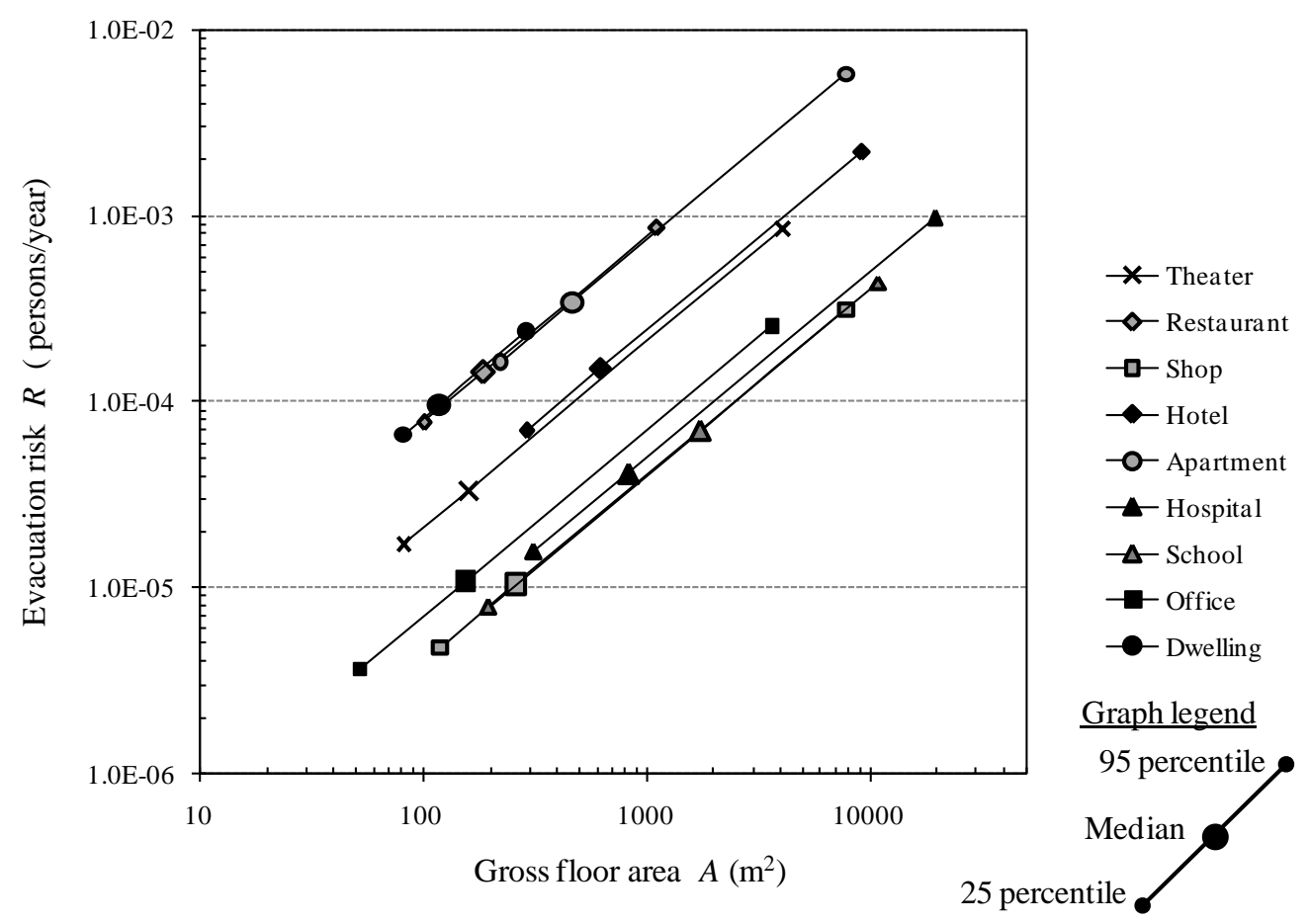

Fig. 7. Range of the evacuation risk $R$ according to the floor area for different building types.

\section{Design-Based Benchmark Evacuation Risk on the Basis of Evacuation Risk in Dwelling}

In the following section, we derive the design-based benchmark evacuation risk $R_{a}^{D}(K)$ on the basis that the evacuation risk in dwelling is set as $R_{a}$. In P-B evacuation safety designs, the number of occupants is normally set by the area assuming a fully loaded condition. The evacuation risk based on the statistical data needs be modified to the value used in the P-B design to apply to the fire safety design. The evacuation risk based on the P-B design, $C_{c a s}$ can be calculated as follows:

$p_{\text {cas }}(H)=C_{c a s}(H) /\left(N_{o c p}(H) \cdot p_{s t y}(H)\right)$ 
To obtain $p_{\text {cas }}$, the data on the number of occupants in buildings at the time of real fires is needed. However, there is no statistical data available for such information. So we estimate the rate of persons at home by Eq. 11 as follows:

$$
p_{s t y}(H)=15.8 / 24=0.66
$$

Where, 15.8 hours/day is a representative value of the times that persons are at home obtained from the National Time Use Survey 2005 [17].

The probability of casualty occurrence, $p_{\text {cas }}$, can be calculated from the ratio of the average number of persons at home and the average number of casualties per hazardous fire. Table 3 is the result of such a trial. With regard to the floor area of the residences, since the detail data is obtained from the Housing and Land Survey [18] and the evacuation risks are calculated by adopting the average area, $125 \mathrm{~m}^{2}$.

Table 3. Trial for design-based casualty toll per hazardous fire in dwelling $\left(C^{D}{ }_{\text {cas }}(H)\right)$

\begin{tabular}{|c|c|c|c|}
\hline Items & Symbols & \begin{tabular}{|r|} 
Units \\
\end{tabular} & Values \\
\hline Mean size of household [18] & $N_{o c p}(H)$ & (Persons) & 3.2 \\
\hline Mean rate of sojorn time at home [17] & $p_{s t y}(H)$ & (Hours/Hours) & 0.66 \\
\hline Mean of number of occupants in fire & $N_{o c p}(H)^{*} p_{s t y}(H)$ & (Persons) & 2.11 \\
\hline Casualty toll per hazardous fire & $C_{\text {cas }}(H)$ & \begin{tabular}{|l}
$($ Person/ \\
Hazardous fire)
\end{tabular} & 0.3 \\
\hline $\begin{array}{l}\text { Probability to be killed or } \\
\text { be injured per hazardous fire }\end{array}$ & $p_{\text {cas }}(H)=C_{\text {cas }}(H) /\left(N_{o c p}(H) * p_{s t y}(H)\right)$ & ( /Hazardous fire) & 0.14 \\
\hline Mean of floor area in dwelling [18] & $A(H)$ & $\left(\mathrm{m}^{2}\right)$ & 125 \\
\hline $\begin{array}{l}\text { Design-based density of } \\
\text { occupant load in dwelling [1] }\end{array}$ & $p^{D}(H)$ & $\left(\right.$ Persons $\left./ \mathrm{m}^{2}\right)$ & 0.06 \\
\hline $\begin{array}{l}\text { Number of evacuee for } \\
\text { evaluation of evacuation }\end{array}$ & $C^{D}{ }_{0}(H)=A(H) * p^{D}(H)$ & (Persons) & 7.5 \\
\hline Design-based casualty toll per hazardous fire & $C^{D}{ }_{\text {cas }}(H)=p_{\text {cas }}(H) * C^{D}{ }_{0}(H)$ & \begin{tabular}{|l} 
(Persons/ \\
Hazardous fire)
\end{tabular} & 1.1 \\
\hline
\end{tabular}

We can calculate the design-based benchmark evacuation risk on the basis of evacuation risk in dwelling for R-B ESDM according to Eq. 8 as follows:

$R_{a 2}^{D}(K)=C_{\text {cas }}^{D}(H)\left(\frac{p_{h f}(H)}{p_{h f}(K)}\right)\left(\frac{A(H)}{A(K)}\right)=1.1\left(\frac{2.8 \cdot 10^{-6}}{p_{h f}(K)}\right)\left(\frac{125}{A(K)}\right)$

For determining design-based benchmark evacuation risk for objective building use, only the value of $p_{h f}$ relative to that of the reference type of use, i.e. dwelling, is sufficient. Table 4 shows the ratio of the $p_{h f}(H)$ to $p_{h f}(K)$, and the value of $R_{a 2}^{D}(K)$ derived from Eq. 8 for various type of use. In Table 4, two types of $R_{a 2}^{D}(K)$ are shown as examples. One is derived from common tentative floor area (in this case, it is $100 \mathrm{~m}^{2}$ ), the other is derived from the median of floor area in each building type in Table 2. The $R^{D}{ }^{2}(K)$ gets smaller, the requirement that the designers should have meet gets higher. As for the values of $R_{a 2}^{D}(K)_{-100}$, they are varied from 0.7 person/hazardous fire in restaurant to 13.3 person/hazardous fire in school. Only the value in restaurant is smaller than that in dwelling. The value of theater is as same as that in dwelling. The value in hospital and school are almost ten-times as large as that in dwelling. In contrast, as for the values of $R_{a 2}^{D}(K)_{\text {mmedian }}$, the values in theater, shop, hotel, apartment and school are smaller than that in dwelling though their values of $R^{D}{ }_{a 2}(K)_{-} 100$ are larger than that in dwelling. These results can be pointed out that the requirement in room-evacuation may be alleviated in theses building types but on the contrary, the requirement for floor or whole-building evacuation may be tightened more. 
Table 4. Ratio of $p_{h f}(H)$ and $p_{h f}(K)$, and the value of $R_{a 2}^{D}(K)$ according to $A(K) \_100$ and $A(K) \_m e d i a n$.

\begin{tabular}{|l|r|r|r|r|r|r|r|r|r|}
\hline & Theater & Restaurant & \multicolumn{1}{c|}{ Shop } & Hotel & Apartment & Hospital & School & Office & Dwellng \\
\hline$C_{\text {cas }}^{D}(H)$ & 1.1 & 1.1 & 1.1 & 1.1 & 1.1 & 1.1 & 1.1 & 1.1 & 1.1 \\
\hline$p_{h f}(H) / p_{h f}(K)$ & 1.2 & 0.5 & 7.2 & 3.1 & 1.5 & 9.0 & 9.7 & 4.1 & 1.0 \\
\hline \hline$A(K) \_100$ & 100 & 100 & 100 & 100 & 100 & 100 & 100 & 100 & 100 \\
\hline $125 / A(K) \_100$ & 1.25 & 1.25 & 1.25 & 1.25 & 1.25 & 1.25 & 1.25 & 1.25 & 1.25 \\
\hline$R_{a 2}^{D}(K) \_100$ & 1.7 & 0.7 & 9.9 & 4.2 & 2.0 & 12.4 & 13.3 & 5.6 & 1.4 \\
\hline \hline$A(K) \_$median & 159 & 187 & 262 & 625 & 464 & 827 & 1731 & 155 & 118 \\
\hline $125 / A(K) \_$median & 0.79 & 0.67 & 0.48 & 0.20 & 0.27 & 0.15 & 0.07 & 0.81 & 1.06 \\
\hline$R_{a 2}^{D}(K) \_$median & 1.0 & 0.4 & 3.8 & 0.7 & 0.4 & 1.5 & 0.8 & 3.6 & 1.2 \\
\hline
\end{tabular}

\section{CONCLUSION}

In this paper we have calculated values of the rate of hazardous fire occurrence, the rate of casualties per hazardous fire and the acceptable evacuation risk for a fire safety design method by using the statistical data on representative building types [10].

(1) The rates of hazardous fire occurrence of nine building types are obtained. The rates show high values in the order of three groups: restaurant; theater, apartment and dwelling; and others.

(2) The evacuation risk is calculated for each use of buildings, using the median gross floor area referred from fire statistical reports. The values of the evacuation risk are high for the building types where people sleep.

(3) The rate of the casualty occurrence per hazardous fire is calculated as 0.14 per hazardous fire, by assuming the average stay time per day in residences as the ratio of persons being home. With this value, the design-based casualty toll per hazardous fire on the basis of evacuation risk in a dwelling is evaluated as 1.1 person/hazardous fire.

(4) A method to calculate the design-based benchmark evacuation risk for R-B ESDM is presented, regarding the evacuation risk in a dwelling based on the occupant load for the fire safety design as standard. Designers should conduct fire safety planning so that the evacuation risk of their buildings is lower than the design-based benchmark evacuation risk.

In this design method, further discussions are needed about how to select the reasonable standard value for the acceptable evacuation risk. For this purpose, we will continue further analysis and obtain more detail of the risk level, and will have more extensive case studies to seek a practical, reasonable level in the context of the risk-based evacuation safety design.

\section{ACKNOWLEDGEMENT}

This study is conducted as the work of the committee of the P-B design of fire the Japan Association for Fire Science and Engineering. We would like to express our appreciation for their helpful cooperation.

\section{REFERENCES}

[1] The Building Center of Japan and Australian Building Codes Board (ed.), Japanese Verification Methods for Determining Safe Evacuation of a Floor and Building, 2005.

[2] Shida, K., Tsujimoto, M. and Yanagisawa, M., (1986) Evaluation Method of Life Risk in Case of Building Fires, Journal of Architecture, Planning and Environmental Engineering No.368: 69-78, Architectural Institute of Japan, (in Japanese).

[3] Bukowski, R.W., "An Overview of Fire Hazard and Fire Risk Assessment in Regulation”, Annual Meeting of ASHRAE, Vol.112 (2), Chicago, IL, 2006, pp. 387-393. 
[4] Chu, G.Q., Chen, T., Sun, Z.H., and Sun, J.H., (2007) Probabilistic Risk Assessment for Evacuees in Building Fires, Building and Environment, Vol. 42, Issue 3: 1283-1290, http://dx.doi.org/10.1016/j.buildenv.2005.12.002

[5] Frantzich, H., Magnusson, S.E., Holmquist, B., and Ryden, J., (1997) Derivation of Partial Safety Factors for Fire Safety Evaluation Using the Reliability Index Beta Method, Fire Safety Science 5: 667-678, http://dx.doi.org/10.3801/IAFSS.FSS.5-667

[6] Hasofer, A.M., and Beck, V.R., (1999) Probability of Death in the Room of Fire Origin: an Engineering Formula, Journal of Fire Protection Engineering, 10: 19-28, http://dx.doi.org/ $\underline{10.1177 / 104239159901000403}$

[7] Hasofer, A.M., Beck, V.R., and Bennetts, I.D., Risk Analysis in Building Fire Safety Engineering, Elsevier, Amsterdam, 2007.

[8] He, Y., Horason, M., Taylor, P., and Ramsay, C., (2003) Stochastic Modeling for Risk Assessment, Fire Safety Science 7: 333-344, http://dx.doi.org/10.3801/IAFSS.FSS.7-333

[9] Magnusson, S.E., and Pettersson, O., (1981) Rational Design Methodology for Fire Exposed Load Bearing Structures, Fire Safety Journal 3: 227-241, http://dx.doi.org/10.1016/0379-7112(81)90046-1

[10] Tanaka, T. and Yamaguchi, J., "Selection of Design Fires in Evacuation Safety Designs of Buildings based on Fire Risk Concept", Proceedings of the Seventh Asia-Oceania Symposium on Fire Science Technology, Hong Kong, China, 2007.

[11] Fire and Disaster Management Agency (ed.), Annual Report on Fires in Japan, Disaster Prevention Division, Ministry of Internal Affairs and Communications, 1996-2005. (Published annually, in Japanese).

[12] Tanaka, T., Nii, D., Yamaguchi, J., Ikehata, Y., and Notake, H., "A Study on Risk-based Evacuation Safety Design Method for Office Buildings", Proceedings of Interflam 2010, University of Nottingham, UK, 2010.

[13] Tanaka, T., (2009) Risk-based Selection of Design Fires to ensure an Acceptable Level of Evacuation Safety, Fire Safety Science 9: 49-61, http://dx.doi.org/10.3801/IAFSS.FSS.9-49

[14] Nii, D., Yamaguchi, J., Ikehata, Y., Notake, H., Deguchi, Y., Kakae, N., and Tanaka, T., "Study on Risk-based Evacuation Safety Method Part 1 to 5", Proceedings of Annual meeting of Japan Association for Fire Science and Engineering, Sapporo, Japan, 2010. (in Japanese)

[15] Ikehata, Y., Notake, H., Yamaguchi, J., and Tanaka, T., "Analysis of Fire Statistics for Establishing Benchmark Fire Risk for Evacuation Safety Designs of Buildings", Proceedings of 8th International Conference on Performance-Based Codes and Fire Safety Design Methods Lund, Sweden, 2010, pp. 85-96.

[16] Nii, D., Yamaguchi, J., Notake, H., Ikehata, Y., and Tanaka, T., "Risk-based Selection of design Fire Scenarios in Performance based Evacuation Safety Designs of Buildings", Proceedings of 8th International Conference on Performance-Based Codes and Fire Safety Design Methods Lund, Sweden, 2010, pp. 97-108.

[17] NHK Broadcasting Culture Research Institute (ed.), NHK Data book 2005 National Time Use Survey, Japan Broadcast publishing, 2006. (Published every five years, in Japanese)

[18] Statistics Bureau (ed.), Data book 2003 Housing and Land Survey, Ministry of Internal Affairs and Communications, 2004. (Published every five years, in Japanese) 